\title{
A Pilot Study of Lay Health Worker Outreach and Colorectal Cancer Screening Among Chinese Americans
}

\author{
Tung T. Nguyen • Mary Beth Love • Cindy Liang • \\ Lei-Chun Fung • Thoa Nguyen • Ching Wong • \\ Ginny Gildengorin $\cdot$ Kent Woo
}

Received: 18 January 2010 / Accepted: 29 January 2010/Published online: 5 March 2010

(C) The Author(s) 2010. This article is published with open access at Springerlink.com

\begin{abstract}
The research team recruited eight Chinese American (seven females, one male) lay health workers (LHWs). They received $12 \mathrm{~h}$ of training about colorectal cancer (CRC), its screening, and basic health education techniques. Each LHW were asked to recruit ten participants and conduct two educational sessions. Of the 81 participants recruited, 73 had not received colorectal cancer screening. Their mean age was 63.0 years, and $72.6 \%$ were women. Knowledge of colorectal cancer, its causes, and its screening increased significantly. Receipt of first colorectal
\end{abstract}

This project was supported by the National Cancer Institute through the SFSU-UCSF Minority-Serving Institution/Cancer Center Partnership (U56CA96216). Dr. Nguyen was also supported by the National Cancer Institute through the Asian American Network for Cancer Awareness, Research, and Training (U01CA114640).

T. T. Nguyen · T. Nguyen • C. Wong · G. Gildengorin

University of California, San Francisco,

44 Page Street, Suite 500,

San Francisco, CA 94102, USA

M. B. Love

San Francisco State University,

1600 Holloway Avenue,

San Francisco, CA 94113, USA

C. Liang $\cdot \mathrm{K}$. Woo

NICOS Chinese Health Coalition,

1208 Mason Street,

San Francisco, CA 94108, USA

L.-C. Fung

Chinatown Public Health Center,

1490 Mason Street, Room 304,

San Francisco, CA 94133, USA

T. T. Nguyen $(\square)$

UCSF Medical Center,

Box 0320, San Francisco, CA 94143, USA

e-mail: Tung.Nguyen@ucsf.edu cancer screening test increased from $0.0 \%$ at baseline to $55.7 \%$ for fecal occult blood tests, 7.1\% for sigmoidoscopy, and $7.1 \%$ for colonoscopy. LHW outreach is feasible and may be effective in promoting CRC screening among Chinese Americans.

Keywords Lay health worker - Colorectal cancer screening . Chinese Americans

\section{Introduction}

Chinese Americans constitute the largest Asian American ethnic group with a population of about 2.8 million [1] Nearly $70 \%$ are foreign-born, with half speaking English less than "very well" [1]. Colorectal cancer is the second most common cancer among Chinese Americans [2], who have incidence rates similar to those of non-Hispanic whites [2]. Asian immigrants have a higher risk of colorectal cancer compared to Asians in Asia, with most of the increase occurring in the first generation [3].

Five-year survival rates for colorectal cancer is greater than $90 \%$ if diagnosed at a local stage [4]. Unfortunately, only $40 \%$ of cases were diagnosed at a local stage among both Chinese and non-Hispanic whites [2]. Colorectal cancer screening reduces mortality [5-7] and is cost effective $[8,9]$. The US Preventive Services Task Force (USPSTF) recommends screening with fecal occult blood test (FOBT) annually, sigmoidoscopy every 5 years, FOBT annually and sigmoidoscopy every 5 years, or colonoscopy every 10 years for average-risk persons' aged 50 to 75 [10]. There is no reliable national data on colorectal cancer screening among Chinese Americans, but in the 2001 California Health Interview Survey, they had lower rates of ever having been screened by FOBT, sigmoidoscopy/ 
colonoscopy, or either $(40 \%, 43 \%$, and $59 \%$, respectively) than non-Hispanic whites $(58 \%, 57 \%$, and $75 \%)$ [11]. After controlling for socioeconomic status and access to care, Chinese Americans were significantly less likely than nonHispanic whites to be screened [12]. There is only one published study of a health education intervention to increase CRC screening among Chinese Americans [13].

Health promotion programs have employed community health educators, often in communities with poor access to resources and information [14-17]. The World Health Organization defined "lay health workers" (LHWs) as those who live in a community, are selected by and accountable to it, and work after receiving a short, defined training [17, 18]. Despite their widespread use, there are few rigorous studies of their effectiveness. A review of the US literature reported that LHWs typically provided education and were effective in increasing access to care such as screening services [17]. A recent review in Hispanic communities reported a need for more evidence of effectiveness [19]. Among African Americans and Latinas, LHWs increased mammography but not Pap testing rates [20-22]. This research group has shown that, among Vietnamese American women, LHWs increased cervical cancer screening in a randomized controlled trial (RCT) [23] and breast cancer screening in a RCT [24]. There is only one published study on the use of LHWs among Chinese Americans [25] and one on LHW outreach for CRC screening in any ethnic group, although there have been several on the use of patient navigators [26-31].

This article reports the results of a pilot communitybased participatory research (CBPR) project to implement a LHW outreach program to address colorectal cancer screening among immigrant Chinese Americans in San Francisco, CA. The goals of the pilot were to assess the feasibility of implementing LHW outreach and to evaluate its effectiveness in increasing the rate of colorectal cancer screening in that population.

\section{Methods}

Phase 1: Planning

Identification of Research Question, Intervention, and Collaborations In 2000, the National Cancer Institute's Center to Reduce Cancer Health Disparities funded the Asian American Network for Cancer Awareness, Research, and Training (AANCART) to develop capacity for cancer control among Asian Americans. San Francisco was an AANCART site with two partners, the Vietnamese Community Health Promotion Project (VCHPP) and the Chinese Community Health Care Association (CCHCA). In 2004, CCHCA and its network of community partners, the Chinese Council, chose colorectal cancer as a health priority. VCHPP presented the concept of using LHWs to promote colorectal cancer screening among Chinese Americans in San Francisco to the Council, which evaluated the concept and agreed that it was culturally appropriate and desirable and had the potential to build outreach and research capacity. The target population was identified as limited English proficient Chinese Americans. The Council appointed one of its members, NICOS Chinese Health Coalition, to work with VCHPP to submit a grant application. A third partner, the Community Health Works program at San Francisco City College and San Francisco State University (SFSU), was involved since it has experience in training community health educators and provided a potential career development option for successful lay health workers. The three partners successfully submitted a research grant application to the SFSU-UCSF Minority-Serving Institution/Cancer Center Partnership. The scope of work and funding were evenly split among the partners. The Institutional Review Boards at SFSU and UCSF approved the research protocols.

Focus Groups The research team conducted two focus groups (one male, one female) among Chinese Americans age 50 and older in Cantonese. A gender concordant bilingual member (LCF, CW) of the research team led each group. Respondents gave their opinions about colorectal cancer, its prevention, colorectal cancer screening, and the concept of learning about such screening from peers. The results of the focus groups informed the development of the LHW materials and training.

Educational Materials Due to time constraint, a bilingual English-Vietnamese colorectal cancer brochure, developed in the English language, translated to Vietnamese, and tested with focus groups as well as in a study, was used. A bilingual team member translated the brochure into traditional Chinese characters. The translation was reviewed by two other bilingual staff and revised. The text along with findings from the focus groups was then incorporated into a LHW manual and a bilingual flipchart. The flipchart was created with appropriate cultural images and pictures of Chinese Americans. It included information about colorectal cancer, its symptoms, its risk factors, and its prevention. The flipchart focused on targeted information such as the high rates of colorectal cancer among the Chinese and included a section of responses to frequently asked questions and beliefs, such as the role of diet in prevention, the need of screening when asymptomatic, and cultural factors such as traditional (herbal) medicine and concepts such as fate. The flipchart emphasized that any of the colorectal cancer screening tests recommended by the USPSTF could be used to screen for colorectal cancer. 
However, during the developmental process, it was clear that there were access problems preventing or delaying timely endoscopic screening in San Francisco. Thus, the flipchart focused on FOBT receipt as an easily accessible test. The flipchart was reviewed by bilingual community members, health care providers, and researchers at a meeting of the Chinese Council and revised prior to printing.

\section{Phase 2: Lay Health Worker Recruitment and Training}

LHW Recruitment Recruitment for LHWs was done primarily through Chinese language newspapers and fliers distributed to community organizations. Of the 111 inquiries, 40 reported finding out through newspaper, 44 from flyers, and 23 from emails and/or word of mouth. Those recruited through newspapers expressed the most interest. Among the inquiries with significant interest, 28 were women and nine were men. Seven women and one man were selected based on their level of interest, communication ability, commitment to the project, and size of their social network. Each LHW could be expected to spend about $50-60 \mathrm{~h}$ in recruitment, training, outreach, and research activities and thus was paid $\$ 1,000$ for their participation in this research project. This amount was chosen based on a CBPR consideration that participants with skills from the community should be adequately compensated for their time on a research project.

$L H W$ Training The training program was developed based on prior training activities done by the SFSU Community Health Works team and incorporating lessons learned by the UCSF team in previous LHW projects. A training manual was also developed in English and translated to traditional written Chinese. The LHWs were trained in two 6-hour training sessions over 2 days. The first day focused on providing an overview of the project, understanding the scope of practice, introduction to basic colorectal cancer information, and basic health and presentation skills, while the second day focused primarily on the logistics to recruitment and outreach, and role play. LHWs were taught how each of the screening tests was done and the preparation needed. They watched a video on how to perform an FOBT. Each LHW completed three FOBT cards at home and then returned them to a physician. On the second training day, the LHWs visited a gastroenterologist's office to become familiar with the equipment and setting for sigmoidoscopy and colonoscopy. Surveys administered before and after the training evaluated the LHWs' understanding of the materials presented in the training.
Phase 3: Intervention Implementation

Participant Recruitment and Retention Each LHW was expected to recruit ten participants, and the eight LHWs recruited 82 participants. Eligibility criteria for participants in the intervention included age 50 and older, selfidentification as Chinese or Chinese American, resident of San Francisco, Chinese or English speaking, and never having received colorectal cancer screening. Recruitment was easy for some LHWs and difficult for others. Those with extensive social networks had little trouble. Out of 355 people approached, 203 were interested. Among those not interested, 18 did not have time, 12 were suspicious or afraid, 15 had other reasons, and the others gave no reason. There were 121 ineligibles (seven aged $<50$ and 114 already had screening). Of the 82 participants, one woman dropped out while filling out the pre-intervention survey. The other 81 completed the first LHW session. One participant died between the first and second session due to an unrelated cause. Of the remaining 80 participants, 77 completed both small group sessions.

LHW Intervention Each participant attended two LHW outreach sessions. The first session focused on knowledge about colorectal cancer, its screening, and recommendations as LHWs presented using the flipchart. The eight LHWs held a total of 21 first sessions with two to eight participants each. The second session, occurring approximately 6-8 weeks later, was to reinforce knowledge, identify problems, and assist in problem solving. There were 18 second sessions. LHWs also made follow-up telephone calls after each session. The purpose of the calls were to (1) remind the participants of the next event (either the second outreach session or the post-intervention survey; (2) assess if the participant had obtained screening yet, and if not, why not; and (3) assist the participant in obtaining screening, either by answering questions or providing encouragement.

Survey Instrument Development and Administration The team developed a survey instrument using item pools from other published studies and incorporating findings from the focus groups. The survey was reviewed in English by all members of the research team and then translated into traditional written Chinese. Two bilingual members of the team reviewed the survey for linguistic and conceptual accuracy. The post-intervention survey repeated knowledge, attitudes, and outcomes measures as well as questions about the program and the participants' dissemination of the information to others. A member of the research team administered the pre-intervention survey at the first LHW session for each participant. The post-intervention survey was administered in person (66 participants) or by 
telephone (11 participants) by a member of the research team approximately 5-6 months after the pre-intervention survey.

Measurements The primary outcome was self-reported receipt of first FOBT. Secondary outcomes included first receipt of sigmoidoscopy and first receipt of colonoscopy. Participants were also asked if they thought about obtaining an FOBT, a sigmoidoscopy, or a colonoscopy if he/she never had one and whether the participant planned on obtaining an FOBT or a sigmoidoscopy/ colonoscopy in the next 12 months. Other variables collected included sociodemographics (age, sex, years in the USA, English fluency, educational attainment, marital status, employment, household income), self-reported health, health care access (usual place for care, health insurance), use of Chinese herbalists, and family history of colorectal cancer. Participants were also asked if they had ever heard of colorectal cancer, colon polyp, FOBT, sigmoidoscopy, or colonoscopy, if they knew the factors associated with colorectal cancer, ways to prevent colorectal cancer, and attitudes about colorectal cancer and its screening.

Analyses Descriptive statistics including means, percents, and $95 \%$ confidence intervals were computed for each variable. Despite the screening process, six participants stated on the pre-intervention survey that they already had an FOBT, one already had sigmoidoscopy, and one both tests prior to participation, leaving 73 participants in the final analyses. To examine the pairwise differences between the pre- and the post-intervention data, McNemar's Chisquare tests for categorical variables and Student's paired $t$ test for continuous variables were used. For knowledge and attitude regarding colorectal cancer, other than those for the screening tests, only those who had heard of colorectal cancer at the time of the survey were included in the analyses. A significance level of $p<0.05$ was used for all statistical tests. Analyses were performed with SAS, Version 9 (SAS Institutes, Cary, NC).

\section{Results}

\section{LHW Characteristics and Training Results}

The male LHW was 66 years old while the ages of the seven female LHWs ranged from 37 to 60 years. Four LHWs were fully employed, one was working part-time and in school, and two were not working. All spoke both Cantonese and Mandarin, and none had any prior health education experience.
All LHWs knew at pre- and post-training that colorectal cancer was preventable and that age 50 was the recommended age for initiation of screening. From pre- to posttraining, more LHWs knew that colorectal cancer was the second most common cancer among Chinese Americans (75\% to $100 \%)$ and that screening tests included FOBT (63\% to $88 \%$ ), sigmoidoscopy ( $0 \%$ to $88 \%$ ), and colonoscopy ( $63 \%$ to $88 \%)$. One LHW did not identify any of the tests at post-intervention and received additional training. At post-training, there was an increase to $100 \%$ from varying levels at pre-training for knowledge of the frequency recommended for screening tests and the risk factors for colorectal cancer.

\section{Results from the LHW Outreach Intervention}

The average age of the 73 participants was 63.0 years, with $53(72.6 \%)$ women (Table 1). The average number of years residing in the USA was 11.8 . Most $(81.7 \%)$ had less than 12 years of education, and $61.6 \%$ had a household income less than $\$ 20,000$ per year. About two thirds had health insurance (63.2\%) and usual place of health care $(63.0 \%)$. More than half (58.9\%) went to Chinese herbalist for some health care. Seventy participants completed both the preand post-intervention surveys. The three who did not were women. Compared to those who completed the study, they were similar in age, marital status, employment, and having health insurance and place of care but had shorter US residence (3.3 years), spoke English poorly/not at all $(100 \%)$, were more educated $(33 \%$ had less than 12 years of education), had more household income (none with household income $<\$ 20,000)$, and had better self-reported health $(66.7 \%$ very good/excellent).

Knowledge about colorectal cancer was limited at preintervention and increased significantly by post-intervention (Table 2). Only $56.9 \%$ and $45.2 \%$ had heard of colon cancer and polyps, respectively, at pre-intervention, but $100.0 \%$ had heard of both by post-intervention. Knowledge of causes of colorectal cancer increased for fatty diet $(36.6 \%$ to $82.9 \%)$, heredity $(24.4 \%$ to $70.7 \%)$, and older age $(12.2 \%$ to $61.0 \%$; all $p \leq 0.0001$ ).

There was a statistically significant increase from pre- to post-intervention in the proportion who believed that screening tests could prevent colorectal cancer $(39.0 \%$ to $82.9 \%, p=0.0002)$. There were no other significant changes from pre- to post-intervention in attitudes and beliefs except an increase in those who were concerned about colorectal cancer $(31.7 \%$ to $65.9 \%, p=0.0005)$.

Awareness of all screening tests increased from $31.7 \%$ to $97.1 \%$ for FOBT $(p<0.0001), 0 \%$ to $97.1 \%$ for sigmoidoscopy, and $38.4 \%$ to $97.1 \%$ for colonoscopy $(p<0.0001)$. Receipt of FOBT increased from $0 \%$ to $55.7 \%$, sigmoidoscopy from $0 \%$ to $7.1 \%$, and colonoscopy from $0 \%$ to $7.1 \%$. 
Table 1 Characteristics of Chinese lay health worker outreach participants

\begin{tabular}{ll}
\hline Demographic characteristics & Mean $(\mathrm{SD})$ or \% $(95 \%$ confidence interval $(N=73)$ \\
\hline Age in years & $63.0(9.8)$ \\
Years in USA & $11.8(9.8)$ \\
Sex, \% women & 72.6 \\
English-speaking ability, poorly/not at all & $79.5(68.4,88.0)$ \\
Education, less than 12 years & $81.7(70.7,89.9)$ \\
Marital status, married/living with partner & $74.0(62.4,83.6)$ \\
Employment & \\
Employed & $16.4(8.8,27.0)$ \\
Unemployed & $27.4(17.6,39.1)$ \\
Homemaker/student/retired & $56.2(44.1,67.8)$ \\
Household income, less than $\$ 20,000 /$ year & $61.6(49.5,72.8)$ \\
Health and access to health care & $12.3(5.8,22.1)$ \\
Self-reported health, very good/excellent & $63.0(50.9,74.0)$ \\
Have usual place for health care & $63.2(49.3,75.6)$ \\
Have health insurance & $58.9(46.8,70.3)$ \\
Go to Chinese herbalist & 0 \\
Has family history of colorectal cancer &
\end{tabular}

There was an increase in those who thought about obtaining an FOBT $(33.3 \%$ to $53.3 \%, p=0.03)$ or colonoscopy (24.7\% to $43.3 \%, p=0.008)$ among those who had never had the test. The proportion who planned on obtaining an FOBT in the next 12 months also increased from $42.5 \%$ to $60.0 \%(p=0.02)$.

There was no difference by sex in the demographics and health care variables, except that men were more likely than women to be married $(90.0 \%$ vs $67.9 \%, p=0.04)$. There was no difference in the variables presented in Table 2 by sex except for one variable. Men were less likely than women to plan on obtaining an FOBT in the next 12 months at pre-intervention $(20.0 \%$ vs $50.9 \%, p=0.02)$ and at postintervention $(40.0 \%$ vs $68.0 \%, p=0.057)$. Among those who remained unscreened, men were less likely to think about obtaining an FOBT (12.5\% vs $68.2 \%, p=0.012)$.

Nearly all (96.1\%) participants reported that the LHWs helped with colorectal cancer prevention, with $73.0 \%$ reporting that LHWs helped to inform about the tests, $67.6 \%$ that LHWs showed where to go for the tests, $78.4 \%$ that LHWs encouraged to get tests, and $40.5 \%$ that LHWs answered questions. Characteristics in LHWs that participants liked were being knowledgeable (67.5\%), helpful $(88.3 \%)$, friendly $(83.1 \%)$, accessible $(66.2 \%)$, and respectful $(71.4 \%)$.

After participating in the LHW program, 26.0\% of participants discussed colorectal cancer screening with one to two other people, $31.2 \%$ with three to four other people, and $36.4 \%$ with five or more other people. After the program, two LHWs participated in health fairs held by NICOS Chinese Health Coalition and taught over 100 participants about colorectal cancer screening using the flipchart. Through the LHW program, one LHW became interested in health outreach and was hired by NICOS to conduct other health-related outreach.

\section{Discussion}

The results of this pilot study indicate that the use of lay health worker outreach to promote colorectal cancer screening is feasible among Chinese Americans and is effective, albeit in an uncontrolled study, in increasing the rate of colorectal cancer screening in this population. Other important findings from this study include preliminary information about how LHW outreach may work in this population and the acceptability of LHW outreach among Chinese American men.

There has been increasing interest on how to increase uptake of health interventions that have been proven effective [32]. Despite the size of the Chinese American population and the lack of adequate colorectal cancer screening, there has been only one published intervention to increase this proven modality in this population-a clinic-based intervention in Seattle, WA using a professional health educator, bilingual materials, and direct provision of FOBT cards [13]. That study found that the intervention was superior to usual care for FOBT receipt. The intervention group had an increase of $69 \%$ in the receipt of colorectal cancer screening, a rate that is slightly higher than the increase of $55 \%$ in this LHW outreach study. The results of both studies show that culturally and linguisti- 
Table 2 Colorectal cancer knowledge, attitudes, beliefs, and screening behaviors among Chinese participants in a lay health worker outreach program

Pre-intervention $(N=73) \quad$ Post-intervention $(N=70) \quad p$ value Mean (SD) or $\%$ ( $95 \%$ confidence interval)

Knowledge about colorectal cancer ${ }^{\mathrm{a}}$

Ever heard of colorectal cancer

Ever heard of colon polyp

Agree that factor is associated with colorectal cancer

Fatty diet

Heredity

Smoking

Lack of physical activity

Older age

Constipation

Toxins

God's will

Bad karma

Attitudes and beliefs ${ }^{\mathrm{a}}$

Ways to prevent colorectal cancer

Regular bowel movements

Chinese herbs

Chinese healer

Aspirin

Drink more water

Eat fibers and vegetables

Screening tests

Nothing

Concerned about colorectal cancer

Arranging schedule for screening is easy

Finding time for screening is difficult

Going through screening would be difficult

Afraid of abnormal screening test

Family thinks I should go through screening

If found early, colorectal cancer can be cured

Colorectal cancer screening knowledge, behaviors, and intention

Ever heard of FOBT

Ever heard of sigmoidoscopy

Ever heard of colonoscopy

Ever had FOBT

Ever had sigmoidoscopy

Ever had colonoscopy

If never had an FOBT, ever thought about obtaining one

If never had a sigmoidoscopy, ever thought about obtaining one

If never had a colonoscopy, ever thought about obtaining one

Plan to obtain FOBT in next 12 months

Plan to obtain sigmoidoscopy or colonoscopy in next 12 months
Personal risk of colorectal cancer is high

$$
\begin{aligned}
& 56.9(44.7,68.6) \\
& 45.2(33.5,57.3) \\
& 36.6(22.1,53.1) \\
& 24.4(12.4,40.3) \\
& 22.0(10.6,37.6) \\
& 24.4(12.4,40.3) \\
& 12.2(4.1,26.2) \\
& 56.1(39.8,71.5) \\
& 12.2(4.1,26.2) \\
& 2.4(0.06,12.9) \\
& 2.4(0.06,12.9)
\end{aligned}
$$

$$
\begin{aligned}
& 48.8(32.9,64.9) \\
& 14.6(5.6,29.2) \\
& 12.2(4.1,26.2) \\
& 4.9(0.6,16.5) \\
& 61.0(44.5,75.8) \\
& 87.8(73.8,95.9) \\
& 39.0(24.2,55.5) \\
& 2.4(0.06,12.9) \\
& 31.7(18.1,48.1) \\
& 70.0(53.5,83.4) \\
& 48.8(32.9,64.9) \\
& 51.3(34.8,67.6) \\
& 4.9(0.6,16.5) \\
& 56.1(39.8,71.5) \\
& 61.0(44.5,75.8) \\
& 97.6(87.1,99.9)
\end{aligned}
$$$$
31.7(23.2,44.7)
$$$$
0.0
$$$$
38.4(31.1,53.5)
$$$$
0.0
$$

\begin{tabular}{|c|c|}
\hline $53.7(37.4,69.3)$ & 0.67 \\
\hline $7.3(1.5,19.9)$ & 0.32 \\
\hline $7.3(1.5,19.9)$ & 0.48 \\
\hline $7.3(1.5,19.9)$ & 0.65 \\
\hline $53.7(37.4,69.3)$ & 0.49 \\
\hline $73.2(57.1,85.8)$ & 0.08 \\
\hline $82.9(67.9,92.9)$ & 0.0002 \\
\hline $4.9(0.6,16.5)$ & 0.56 \\
\hline $65.9(49.4,79.9)$ & 0.0005 \\
\hline $63.4(46.9,77.9)$ & 0.49 \\
\hline $43.9(28.5,60.3)$ & 0.67 \\
\hline $53.7(37.4,69.3)$ & 0.83 \\
\hline $17.5(7.3,32.8)$ & 0.06 \\
\hline $58.5(42.1,73.7)$ & 0.76 \\
\hline $73.7(56.9,86.6)$ & 0.21 \\
\hline $97.6(87.1,99.9)$ & 1.00 \\
\hline $97.1(90.9,99.7)$ & $<0.0001$ \\
\hline $97.1(90.9,99.7)$ & - \\
\hline $97.1(89.0,99.2)$ & $<0.0001$ \\
\hline $55.7(47.9,70.8)$ & - \\
\hline $7.1(2.9,16.2)$ & - \\
\hline $7.1(2.1,14.5)$ & - \\
\hline $53.3(34.3,71.7)$ & 0.03 \\
\hline $42.9(30.2,54.5)$ & 0.22 \\
\hline $43.3(29.8,54.5)$ & 0.008 \\
\hline $60.0(50.6,73.1)$ & 0.02 \\
\hline $58.7(45.3,74.2)$ & 0.05 \\
\hline
\end{tabular}$$
0.0
$$$$
0.0
$$$$
33.3(22.1,45.1)
$$$$
31.5(22.2,44.1)
$$$$
24.7(17.0,37.3)
$$$$
42.5(33.4,55.9)
$$

$36.4(26.1,51.2)$
100.0

100.0

$82.9(67.9,92.9)$

$<0.0001$

$70.7(54.5,83.9)$

$<0.0001$

$75.6(59.7,87.6)$

$<0.0001$

$63.4(46.9,77.9)$

0.0003

$61.0(44.5,75.8)$

$<0.0001$

$87.8(73.8,95.9)$

0.0008

$43.9(28.5,60.3)$

0.003

$0.0(-)$

$-$

$0.0(-)$

$S D$ standard deviation

${ }^{a}$ Only those who had heard of colorectal cancer at the time of the survey were included in the knowledge and attitude variables analyses 
cally appropriate health education, whether community- or clinic-based, can lead to large increases in the rate of colorectal cancer screening among Chinese Americans.

In addition to the effect on increasing colorectal cancer screening, the LHW outreach participants also increased their knowledge about the known risk factors of colorectal cancer. There was an increase in the knowledge that screening prevents colorectal cancer, although there was no change in knowledge of other prevention modalities such as eating fibers and vegetables or taking aspirin to prevent colorectal cancer. This was because, for simplicity, the intervention focused on screening, and thus, the LHWs did not discuss other modalities other than to acknowledge that they were valid. The lack of emphasis may have led the participants to believe that the other preventive methods may not be effective. Since those other behaviors should be encouraged, this would be an issue to address in future studies.

There was an increase in concern about colorectal cancer, but no changes in the perception of logistical barriers. This is likely a result of the way this LHW outreach program was structured, with the main focus on knowledge and risk, and, other than providing participants with referral to places to go to obtain screening, less focus on providing navigation support. This feature separates the type of outreach conducted by LHWs from patient navigators, one of whose main functions is to provide navigation and logistical support. Future studies with LHWs could include additional components that address logistical problems.

Rogers argued that, among the five stages of diffusion theory's adoption process - knowledge, persuasion, decision, trial, and adoption-interpersonal contact and social networks are more influential than other modalities, such as mass media, in driving the last two or three phases [33]. Lay health workers in this study successfully transmitted knowledge about colorectal cancer and its screening to their participants. Most participants acknowledged that knowledge delivery was a key component of the LHW outreach, but they reported that the LHWs also helped to provide other important information such as logistics (e.g., where to go to obtain screening) and emotional support to encourage the participants to get screened. Participants also selected the characteristics of being helpful, friendly, and respectful more frequently than being knowledgeable as what they liked about their LHWs. Although this study was not designed to address the question of how LHW outreach works, these interpersonal qualities may have been as important as knowledge diffusion in increasing adoption of colorectal cancer screening among the participants. LHW outreach should be strongly considered in programs that work with minority populations such as Chinese Americans because LHWs have natural cultural and linguistic competence, because LHWs fit the needs of diffusion theory, and there is increasing empirical evidence, including this study, for the effectiveness of LHW outreach [20-24, 34].

A recent review of LHW outreach reported a need for studies with male participants [19]. This study showed that it is feasible to implement LHW outreach for Chinese American men on the topic of colorectal cancer screening. Interestingly, even though some female LHWs worked with male participants, there were minimal differences in the effect of the intervention on knowledge and uptake of colorectal cancer screening between male and female participants. However, men did have lower rates of intention to obtain screening in the future. It was also harder to find qualified men interested in becoming LHWs. These findings suggest that concerns remain about the applicability of LHW outreach methods to ethnic minority men and that LHW outreach with these men should be tested in a larger study.

An important and often underappreciated feature of LHW outreach programs is the building of community capacity to address health concerns. In this study, this occurred in three ways. First, existing social networks, which were probably channels of communication about a variety of issues, including health concerns, were utilized to spread the word about an evidence-based effective intervention, colorectal cancer screening. The message did not stop after the participants listened to the LHWs because many participants reported discussing colorectal cancer screening with others in their networks. Utilizing the social networks in this way may prepare for future health-related outreach by setting the norm for those in the network that this is an acceptable content for communication. Secondly, the LHWs become ready resources for further linguistically and culturally competent interventions on health. This did occur in a direct way, when NICOS utilized trained LHWs to provide teaching about colorectal cancer screening to large numbers of participants at health fairs. The presentation and research skills that they learned will also prepare them to conduct similar work on other health topics. On a more fundamental level, some LHWs become activated to work in health outreach, as in the example of the LHW who then seeked and obtained further employment with NICOS. Finally, the capacity of a community organization such as NICOS to work in research and in cancer prevention also increased, and it is currently working with this team of researchers on other funded projects to carry out community-based participatory research among Chinese Americans.

This study has several important limitations. As a feasibility study, the sample size was small, and there was no control group. The outcome of colorectal cancer screening was based on self-reports, not on medical record validation, and little is known about the validity of selfreports for colorectal cancer screening among Asian Americans. 
The findings from this study show that LHW outreach to promote colorectal cancer screening among Chinese American men and women is feasible and possibly effective. Further studies are needed to document the effectiveness of this culturally appropriate intervention and to describe the mechanisms through which this intervention works.

Open Access This article is distributed under the terms of the Creative Commons Attribution Noncommercial License which permits any noncommercial use, distribution, and reproduction in any medium, provided the original author(s) and source are credited.

\section{References}

1. US Census Bureau, The American Community-Asians (2004) The American Community Survey Reports 2007. US Department of Commerce, Washington DC

2. Miller BA, Chu KC, Hankey BF et al (2008) Cancer incidence and mortality patterns among specific Asian and Pacific Islander populations in the US. Cancer Causes Control 19(3):227-256

3. Le Marchand L, Wilkens LR, Kolonel LN et al (1997) Associations of sedentary lifestyle, obesity, smoking, alcohol use, and diabetes with the risk of colorectal cancer. Cancer Res 57 (21):4787-4794

4. Vernon SW (1997) Participation in colorectal cancer screening: a review. J Natl Cancer Inst 89(19):1406-1422

5. Selby JV, Friedman GD, Quesenberry CP Jr et al (1992) A casecontrol study of screening sigmoidoscopy and mortality from colorectal cancer. N Engl J Med 326(10):653-657

6. Mandel JS, Bond JH, Church TR et al (1993) Reducing mortality from colorectal cancer by screening for fecal occult blood. Minnesota Colon Cancer Control Study. N Engl J Med 328 (19):1365-1371

7. Hardcastle JD, Chamberlain JO, Robinson MH et al (1996) Randomised controlled trial of faecal-occult-blood screening for colorectal cancer. Lancet 348(9040):1472-1477

8. Maciosek MV, Solberg LI, Coffield AB et al (2006) Colorectal cancer screening: health impact and cost effectiveness. Am J Prev Med 31(1):80-89

9. Maciosek MV, Coffield AB, Edwards NM et al (2006) Priorities among effective clinical preventive services: results of a systematic review and analysis. Am J Prev Med 31(1):52-61

10. US Preventive Services Task Force (2008) Screening for colorectal cancer: U.S. Preventive Services Task Force recommendation statement. Ann Intern Med 149(9):I44

11. Wong ST, Gildengorin G, Nguyen T et al (2005) Disparities in colorectal cancer screening rates among Asian Americans and non-Latino whites. Cancer 104(12 Suppl):2940-2947

12. Kandula NR, Wen M, Jacobs EA et al (2006) Low rates of colorectal, cervical, and breast cancer screening in Asian Americans compared with non-Hispanic whites: cultural influences or access to care? Cancer 107(1):184-192

13. Tu SP, Taylor V, Yasui Y et al (2006) Promoting culturally appropriate colorectal cancer screening through a health educator: a randomized controlled trial. Cancer 107(5):959-966

14. Israel BA (1985) Social networks and social support: implications for natural helper and community level interventions. Health Educ Q 12(1):65-80
15. Brownstein JN, Cheal N, Ackermann SP et al (1992) Breast and cervical cancer screening in minority populations: a model for using lay health educators. J Cancer Educ 7(4):321-326

16. Schulz AJ, Israel BA, Becker AB et al (1997) "It's a 24-hour thing... a living-for-each-other concept": identity, networks, and community in an urban village health worker project. Health Educ Behav 24(4):465-480

17. Swider SM (2002) Outcome effectiveness of community health workers: an integrative literature review. Public Health Nurs 19 (1): $11-20$

18. WHO (1987) Community health workers: working document for the WHO study group. World Health Organization, Geneva

19. Rhodes SD, Foley KL, Zometa CS et al (2007) Lay health advisor interventions among Hispanics/Latinos: a qualitative systematic review. Am J Prev Med 33(5):418-427

20. Sung JF, Blumenthal DS, Coates RJ et al (1997) Effect of a cancer screening intervention conducted by lay health workers among inner-city women. Am J Prev Med 13(1):51-57

21. Navarro AM, Senn KL, McNicholas LJ et al (1998) Por La Vida model intervention enhances use of cancer screening tests among Latinas. Am J Prev Med 15(1):32-41

22. Slater JS, Ha CN, Malone ME et al (1998) A randomized community trial to increase mammography utilization among low-income women living in public housing. Prev Med 27 (6):862-870

23. Mock J, McPhee SJ, Nguyen T et al (2007) Effective lay health worker outreach and media-based education for promoting cervical cancer screening among Vietnamese American women. Am J Public Health 97(9):1693-1700

24. Nguyen TT, Le G, Nguyen T et al (2009) Breast cancer screening among Vietnamese Americans: a randomized controlled trial of lay health worker outreach. Am J Prev Med 37(4):306-313

25. Engelstad LP, Stewart S, Otero-Sabogal R et al (2005) The effectiveness of a community outreach intervention to improve follow-up among underserved women at highest risk for cervical cancer. Prev Med 41(3-4):741-748

26. Campbell MK, James A, Hudson MA et al (2004) Improving multiple behaviors for colorectal cancer prevention among African American church members. Health Psychol 23(5):492-502

27. Nash D, Azeez S, Vlahov D et al (2006) Evaluation of an intervention to increase screening colonoscopy in an urban public hospital setting. J Urban Health 83(2):231-243

28. Chen LA, Santos S, Jandorf L et al (2008) A program to enhance completion of screening colonoscopy among urban minorities. Clin Gastroenterol Hepatol 6(4):443-450

29. Christie J, Itzkowitz S, Lihau-Nkanza I et al (2008) A randomized controlled trial using patient navigation to increase colonoscopy screening among low-income minorities. J Natl Med Assoc 100 (3):278-284

30. Myers RE, Hyslop T, Sifri R et al (2008) Tailored navigation in colorectal cancer screening. Med Care 46(9 Suppl 1):S123-S131

31. Lasser KE, Murillo J, Medlin E et al (2009) A multilevel intervention to promote colorectal cancer screening among community health center patients: results of a pilot study. BMC Fam Pract 10:37

32. Green LW, Ottoson JM, Garcia C et al (2009) Diffusion theory, and knowledge dissemination, utilization, and integration in public health. Annu Rev Public Health 30:151-174

33. Rogers EM (2003) Diffusion of innovations, 5th edn. Free Press, New York

34. Bird JA, McPhee SJ, Ha NT et al (1998) Opening pathways to cancer screening for Vietnamese-American women: lay health workers hold a key. Prev Med 27(6):821-829 